\title{
O SETOR ELÉTRICO BRASILEIRO ENTRE AS TRANSFORMAÇÕES CONTEMPORÂNEAS: 0 caso da crise elétrica em $2001^{1}$
}

\section{THE BRAZILIAN ELECTRIC SECTOR AMONG CONTEMPORARY TRANSFORMATIONS: the case of the electrical crisis in 2001}

\author{
Alessandro Andre Leme ${ }^{2}$ \\ lemeaa@gmail.com \\ alessandroleme@,id.uff.br
}

\section{Resumo}

Com a crise no setor elétrico brasileiro em maio de 2001, muitos questionamentos foram levantados acerca das reformas realizadas no mesmo - privatização. Aqui vamos dar ênfase à dois deles. O primeiro se referiu ao tipo de estratégia para o desenvolvimento escolhido pelo governo (Fernando Henrique Cardoso) que consistia nas privatizações dos serviços públicos (eletricidade e telefonia). Seria está escolha a mais adequada para o setor e para o Estado? A outro, por sua vez, se refere a análise da crise (apagão), ou seja, quais fatores e/ou causas a teriam gerado? Seria a crise um processo inevitável ou um resultado decorrente de escolhas opções e estratégias realizadas no âmbito do governo para realização das reformas orientadas para o mercado no setor elétrico? Por meio de pesquisa documental, bibliográfica e entrevistas, visamos desnudar a relação entre as reformas orientadas para o mercado - neoliberais - e a crise ocorrida no setor elétrico em 2001. Um dos resultados da pesquisa apontaram para dois aspectos centrais, a saber: as escolhas de determinadas orientações político-econômicas no âmbito governamental e Estatal foram decisivos para a deflagração da crise no setor e, os impactos da crise foram desiguais na sociedade, sendo os mais pobres os mais atingidos negativamente nas práticas tarifárias. Uma reflexão crítica acerca deste processo é de fundamental importância para compreensão da crise, do contexto e das estratégias adaptadas à época.

Palavras chave: Estado, Neoliberalismo, Privatização, Reformas orientadas para o Mercado, Crise no Setor Elétrico Brasileiro

\footnotetext{
${ }^{1}$ Este artigo contou com apoio da FAPERJ e do CNPq.

2 Doutor em Ciência Política pela UNICAMP. Atualmente é professor do Departamento de Sociologia e do Programa de Pós-Graduação em Sociologia da Universidade Federal Fluminense - UFF
} 


\begin{abstract}
With the crisis in the Brazilian electricity sector in May 2001, many questions were raised about the reforms carried out in the same - privatization. Here we will emphasize both of them. The first referred to the type of development strategy chosen by the government (Fernando Henrique Cardoso) which consisted of privatization of public services (electricity and telephony). Is this choice the most appropriate for the sector and for the state? The other, in turn, refers to the analysis of the crisis (blackout), ie, what factors and/or causes would have generated it? Is the crisis an inevitable process or a result of choices, choices and strategies made within the government to carry out market-oriented reforms in the electricity sector? Through documentary, bibliographical research and interviews, we aim to uncover the relationship between market-oriented reforms - neoliberals - and the crisis that occurred in the electric sector in 2001. One of the results of the research pointed to two central aspects, namely: the choices of certain political-economic orientations at the governmental and state levels were decisive for the outbreak of the crisis in the sector and the impacts of the crisis were unequal in society, being the poorest, most affected by tariff practices. A critical reflection on this process is of fundamental importance for understanding the crisis, the context and the strategies adopted to the time.
\end{abstract}

Keywords: State, Neoliberalism, Privatization, Market-oriented reforms, Crisis in the Brazilian Electricity Sector

\title{
O setor elétrico brasileiro na década de 1990: perspectivas, crise e mudanças
}

A geração de energia elétrica no Brasil foi se constituindo a partir da produção hidrelétrica, consolidando com isto, um parque gerador que aproveitou as grandes quantidades de águas interiores (bacias e rios) que o país possui. Num primeiro momento, do final do século XIX até meados da década de 1950, o setor foi conduzido pelo capital privado, especialmente por duas grandes multinacionais (Light e Amforp), ambas também com forte atuação no setor mexicano neste mesmo período. A partir da década de 1950, em virtude da forte pressão para aumento na oferta e na distribuição de eletricidade, o Estado começa a assumir o setor de energia elétrica como estratégico para o país e para o desenvolvimento urbano-industrial. Com isto, vai tomando forma o 
setor elétrico estatal (que toma a forma de uma holding, com estrutura federal, estadual e minoritariamente municipal). Este sistema perdurou até 1995 (governo FHC), quando são alteradas as leis de concessões e o setor elétrico é aberto ao setor privado via privatizações.

O setor elétrico brasileiro apresentou uma estrutura vertical envolvendo um parque gerador em uma ponta, a transmissão no meio e, na outra ponta, a distribuição. Através de uma estrutura hierarquizada (holding) o Estado controlava todas as fases do processo (geração, transmissão e distribuição). Porém, com os novos arranjos político-institucionais da década de 1990 para o setor elétrico, essa estrutura começou a mudar para um modelo de integração horizontal, ou seja, houve uma mudança da estrutura estatal hierarquizada para outra estrutura baseada em empresas privadas e na livre concorrência do mercado de energia elétrica. Essa estrutura horizontal passaria a contar com geradores e distribuidores independentes e transmissão mista. (LEME, 2005).

A reforma no setor elétrico brasileiro se deu na década de 1990, juntamente com outras reformas. O processo de reestruturação do setor elétrico acirra-se a partir de 1993 com a promulgação da Lei $n^{\circ} 8.631^{3}$. Em 1995, com a promulgação da Lei das Concessões no 8.987 e do Decreto $\mathrm{n}^{\circ} 9.074$, que regulamentaram o artigo 175 da Constituição ${ }^{4}$, criaram-se as condições legais para que os geradores e distribuidores de energia elétrica pudessem competir pelo suprimento dos grandes consumidores de energia elétrica.

O processo de privatização dos setores de geração e transmissão de energia elétrica de viam ser acompanhados por uma regulação do Estado. Porém, a privatização começou a ser implementada antes que o Estado tivesse criado os mecanismos necessários para a nova regulação do setor. A ANEEL (Agência Nacional de Energia Elétrica) foi criada somente em 6 de outubro de 1997, por meio da aprovação do Decreto n 2.335. A ANEEL veio exercer a função de órgão

\footnotetext{
3 Esta Lei eliminou o regime tarifário pelo custo de serviço, abrindo espaço para o processo de criação do Produtor Independente de Energia (PIE) e o estabelecimento de regras para fixação de níveis tarifários, além de estabelecer a obrigatoriedade de contratos de suprimento de energia (contendo quantidades e preços) (Ferreira, 2000).

$4 \mathrm{O}$ artigo 175 incumbiu "ao Poder Público, na forma da lei, diretamente ou sob regime de concessão ou permissão, sempre através de licitação, a prestação de serviços públicos. - Parágrafo único. A lei disporá sobre: o regime das empresas concessionárias e permissionárias de serviços públicos, o caráter especial de seu contrato e de sua prorrogação, bem como as condições de caducidade, fiscalização e rescisão da concessão ou permissão; os direitos dos usuários; política tarifária; a obrigação de manter serviço adequado".
} 
regulador em nível federal, substituindo o DNAEE (Departamento Nacional de Águas e Energia Elétrica) e reordenando as áreas de negócios do setor em: produção de energia (geração); transporte nas tensões mais altas (transmissão); transporte com o específico objetivo de atendimento aos consumidores finais (distribuição); e vendas no varejo, com a função de medir e conquistar os consumidores finais (comercialização).

$\mathrm{Na}$ esfera regional, também foram criadas 12 agências reguladoras estaduais, vinculadas a ANEEL. Elas visavam atender às especificidades da regulação do setor elétrico dos Estados. Foram criadas agências: na região Norte, a ARCON (estado do Pará); na região Nordeste, a ARCE (estado do Ceará), ARSEP (estado do Rio Grande do Norte), a ARPE (estado de Pernambuco), a ASES (estado de Sergipe) e a AGERBA (estado da Bahia); na região Sudeste a AGERSA (estado do Espírito Santo), a ASEP (estado do Rio de Janeiro) e a $\operatorname{CSPE}^{5}$ (estado de São Paulo); na região Centro Oeste a AGER/MT (estado do Mato Grasso) e a AGR (estado de Goiás); e por fim na região Sul a AGERGS (estado do Rio Grande do Sul).

A aquisição das concessionárias por empresas privadas estrangeiras contou com a ajuda do BNDES via financiamento. Para implementar a reestruturação do setor elétrico brasileiro, o Ministério de Minas e Energia (MME) contratou em 1996 um consórcio, formado pelas empresas de consultoria internacional Coopers \& Lybrand e Lathan \& Watkins e pelas empresas nacionais Main e Engevix (ambas do ramo de engenharia, gerenciamento de projetos e obras). Recorreu também a uma empresa de consultoria na área jurídica, a Ulhôa Canto, Rezende e Guerra, visando colher sugestões para a montagem de um novo desenho para o mercado elétrico brasileiro e de uma nova aparência institucional. Do trabalho destas empresas surgiu o "Projeto de Reestruturação do Setor Elétrico Brasileiro - RESEB”, Longo e Bermann (2002:364). A expectativa do governo era de que os trabalhos da consultoria gerassem sugestões que se valessem de experiências das reformas ocorridas em outros países (principalmente as reformas na Grã-Bretanha), nelas buscando

\footnotetext{
${ }^{5}$ Posteriormente transformada em ARSESP - Agência Reguladora de Saneamento e Energia do Estado de São Paulo
} 
O SETOR ELÉTRICO BRASILEIRO ENTRE AS TRANSFORMAÇÕES CONTEMPORÂNEAS: o caso da crise elétrica em 2001

Alessandro Andre Leme

ensinamentos para adaptar ao caso do setor elétrico brasileiro, considerando as suas especificidades. (Ferreira, 2000).

Dentre as especificidades do caso brasileiro, o Governo Federal assinalava as seguintes:

a) por ser federativo, o regime brasileiro torna indispensável a divisão dos poderes regulatórios entre o governo federal e os governos estaduais. Esta divisão se traduz em uma delicada negociação política numa circunstância em que as empresas elétricas controladas pelos governos estaduais já estão sendo privatizadas (Abrucio \& Costa, 1998:91);

b) o sistema elétrico brasileiro é de base hidráulica, sendo necessário forte coordenação da operação na introdução do processo de concorrência na geração;

c) a rede de transmissão brasileira deveria buscar progressivamente interconectar-se em um sistema nacional;

d) dadas as significativas diferenças regionais e empresariais, alguns mecanismos de compensação regionais precisariam subsistir por um período significativo;

e) a existência de um grande número de empresas controladas por governos estaduais, muitas delas com significativos ativos de transporte e geração, exigiria a convivência de empresas privadas e estaduais no mercado elétrico brasileiro durante um período (Rezende \& Paula, 1997:54).

As principais sugestões da Coopers \& Lybrand e demais consultorias que foram aceitas pelo governo brasileiro foram:

a) a criação de um mercado atacadista de eletricidade - $\mathrm{MAE}^{6}$;

\footnotetext{
${ }^{6} \mathrm{O}$ MAE exerce a função de intermediador de todas as transações de compra e venda de energia elétrica dos sistemas elétricos interligados. No Brasil houve a criação de quatro sub-mercados "spot", quais sejam: Norte, Nordeste, Sudeste e Sul-Centro-Oeste. Participam do MAE os geradores com capacidade igual ou superior a 50 MW, todos os varejistas com carga igual ou superior a $100 \mathrm{GWh}$ e todos os grandes consumidores com demandas acima de 10 MW (Tolmasquim e Campos, 2002). No modelo atual (Governo Lula) o MAE é substituído pela Câmara de Comercialização de Energia Elétrica para atuar nos dois ambientes de contratação (Ambiente de Contratação Regulada - ACR e o Ambiente de Contratação Livre - ACL).
} 
b) o estabelecimento de 'contratos iniciais' para criar uma fase de transição para o mercado de energia elétrica competitivo;

c) o desmembramento dos ativos de transmissão e a criação de um Operador Independente do Sistema (OIS) para administrar o sistema interligado;

d) a organização das atividades financeiras e de planejamento neste novo cenário (Ferreira, 2000).

No campo específico da geração, as recomendações também foram significativas no que tange à transparência e ao acesso livre ao mercado. No conjunto das recomendações, destacam-se as seguintes:

a) a desverticalização da geração no que se refere aos ativos federais e estaduais por meio da criação de empresas separadas de geração, as denominadas "gencos" para garantir que o acesso ao mercado de atacado seja livre;

b) a separação horizontal das duas maiores "gencos" federais, FURNAS e CHESF, para criação de duas novas empresas menores a partir de cada uma delas (Longo e Bermann, 2002).

Deste modo, não nos parece que a consultoria se ateve plenamente à realidade brasileira, na qual o mercado atacadista não iria, no médio prazo, incluir novos produtos como a energia por fontes térmicas (óleo, gás, carvão e nuclear como na Inglaterra). Outro equívoco relevante da consultoria foi ter desprezado em suas análises, o controle das cheias, irrigação, abastecimento de água potável, navegação e desenvolvimento regional integrado, questões que são vitais para a nova modelagem energética no Brasil (Rezende \& Paula, 1997 e Meireles, 1999).

Neste sentido, as reformas no setor elétrico brasileiro ficaram marcadas por um processo que respondeu menos aos interesses dos cidadãos/consumidores de energia elétrica do país do que às estratégias das empresas concessionárias - em sua maioria estrangeiras ${ }^{7}$ - que entram no

\footnotetext{
7 AES (Estados Unidos), Houston (Estados Unidos), CEA (Estados Unidos), Enron (Estados Unidos), Duke-Energy (Estados Unidos), Tractebel (Bélgica), EDF (Francesa), EDP (Portuguesa), Endesa (Espanha), Iberdrola (Espanha), Endesa (Chile), e Chilectra (Chile) são apenas algumas das empresas transnacionais que participam da distribuição e geração de energia elétrica brasileira.
} 
mercado nacional de energia elétrica. Tal situação corresponde a uma realidade heterônoma ${ }^{8}$ marcada pela disputa dos interesses das empresas transnacionais do setor em questão.

Propõe-se analisar a privatização numa perspectiva histórico-estrutural ${ }^{9}$ e estratégica, perante a qual, é possível constatar a ocorrência de modificações na relação entre o Estado e o setor privado. Embora as características da privatização seja a transferência de ativos e de capital, há especificidades na forma como o Estado busca legitimidade social para efetivar tal processo, bem como também, há especificidades nas razões que o levam a escolher esse processo. (Leme, 2010).

As empresas públicas de energia que foram privatizadas surgiram num momento histórico, em que, particularmente o Brasil, estava em fase de substituição das importações, precisando de indústrias e serviços que melhorassem a infraestrutura. O setor público surge no campo da energia elétrica como uma proposição pragmática, voltada para a promoção do desenvolvimento a partir de alavancagens produtivas e financeiramente custeadas pelo Estado.

O processo de privatização ocorrido incisivamente na década de 1990 ocasionou alterações significativas nos arranjos institucionais do setor, e, ao mesmo tempo redefiniu e/ ou criou novos agentes e atores para atuarem no setor. A privatização do setor elétrico brasileiro nos anos 1990 foi maior na distribuição (Federal e estadual), aproximadamente 80\%, enquanto na geração (Federal e estadual), apenas 20\% aproximadamente foram privatizadas. LEME, 2005.

\footnotetext{
8 Este processo de heteronomia do poder político nacional já foi amplamente debatido por Fernandes (1981). Para o autor, tal processo tem historicamente criado situações onde os rumos nacionais são fortemente influenciados por interesses exógenos e tem se atrelado à rede de relações político-econômico tradicionais do Estado Brasileiro, formando um compósito deletério ao pleno desenvolvimento social da nação. (Fernandes, 1981).

9 O conceito de processo histórico-estrutural nos parece aqui particularmente interessante por permitir, no âmbito metodológico, a necessária fusão entre estrutura e história na análise social. Isto porque, sob tal perspectiva, as estruturas são concebidas como produto da luta social e como resultado da imposição social, sendo, deste modo, analisadas diante de processos. Conforme bem observa Cardoso (1993: 97), "a ideia de que existe uma explicação histórico-estrutural tem a ver com o processo de formação das estruturas e, simultaneamente, com a descoberta das leis de transformação dessas estruturas. Trata-se de conceber as estruturas como relações entre os homens que, se bem são determinadas, são também (...) passiveis de mudança, à medida que, na luta social (política, econômica cultural), novas alternativas vão se abrindo à prática histórica. Neste sentido, o objeto da análise não se reifica em atores, mas se dinamiza em conjuntos de relações sociais." (grifos, itálicos e negritos nossos).
} 
Por fim, encontra-se neste novo arranjo político-institucional, diversos atores vinculados aos debates sobre os Recursos Hídricos. Eles participam dos órgãos setoriais envolvidos com a hidroeletricidade (Comitês de Bacias e Câmaras Técnicas no MME e na ANEEL), assim como também dialogam para a produção de inventários de bacias (com a $\mathrm{CCPE}^{10}$, ANEEL e ANA); atuam também na definição de critérios gerais para a elaboração de Plano Diretor para os reservatórios no Conselho Nacional de Recursos Hídricos (CNRH), entre outras funções e formas de atuação.

Com isto, fica evidente que a reflexão e implementação de políticas no que concerne à reestruturação do setor elétrico brasileiro, passa necessariamente pela compreensão e pela possibilidade histórica de interpretar e explicar o conjunto de relações nas quais o setor se encontra envolvido, ou seja, relacionando-o com a sustentabilidade que envolve de forma sinérgica a energia, a equidade social, o meio ambiente, o emprego e a democracia.

Destaca-se que toda esta estrutura e atores envolvidos direta ou indiretamente com o setor elétrico brasileiro passaram por um marco político e simbólico muito relevante que foi a crise no setor em $2001^{11}$.

Com a deflagração da crise no setor elétrico brasileiro, em maio de 2001, algumas questões acerca da forma como o setor foi estruturado no país e a fonte majoritária de geração e produção de energia elétrica foram questionadas. Por outro lado, veiculou-se na época que tal estrutura de

10 - Comitê Coordenador do Planejamento da Expansão dos Sistemas Elétricos - CCPE, criado pela Portaria N. 150, de 10 de maio de 1999, pelo Ministério das Minas e Energia (MME).

11 - A crise do setor elétrico, ou "crise do apagão" conforme ficou conhecida consistiu nos cortes forçados e metas de diminuição de gastos (consumo) de energia elétrica, assim como também a ocorrência de alguns Blecautes. Por outro lado, a implantação do racionamento (metas de consumo definidas por classe - industrial, residencial, entre outras) fez com que os impactos negativos fossem menores. Isto porque os investimentos no setor (por ser hidrelétrico) demandam um tempo longo de maturação. Como a opção do governo foi deixar as empresas atrativas ao capital privado, as mesmas (que já vinham estranguladas desde meados da década de 1980) foram proibidas de investir, gerando com isto uma situação muito tênue entre o equilíbrio da oferta/demanda e a crise, deflagrando-se em 2001 a crise no setor. 
O SETOR ELÉTRICO BRASILEIRO ENTRE AS TRANSFORMAÇÕES CONTEMPORÂNEAS: o caso da crise elétrica em 2001

geração centrada prioritariamente na fonte hidrelétrica deixava o setor e, consequentemente, o país, refém das chuvas para encherem os reservatórios.

Atribuía-se que um setor fundamental para o desenvolvimento e reprodução das sociedades capitalistas, tal qual o da eletricidade, estruturava-se principalmente em um fator no qual o homem não controla, a chuva. Rompendo com isto, ao menos no discurso, com um dos principais fatores de organização do mundo moderno - a racionalidade no âmbito do Estado ${ }^{12}$, inaugurado por Maquiavel no século XVI, mas também desenvolvido por Max Weber, já no século XX, para ater-se apenas a dois autores de relevância para as ciências sociais.

Partindo desta aparente contradição entre a forma com que o Estado Moderno se organiza (a partir de procedimentos racionais) e o discurso oficial veiculado por ocasião da crise no setor elétrico em 2001, verifica-se que o principal fundamento dos gestores era a negação da racionalidade na organização e estruturação do Estado. Em outras palavras, deixava-se um dos seus fatores estruturantes (geração/produção de eletricidade) fora do domínio e controle do homem.

\section{A CRISE DO SETOR ELÉTRICO BRASILEIRO EM 2001: o caso emblemático do racionamento entre a Virtù e a Fortuna.}

Em maio de 2001, deflagrou-se uma crise do setor elétrico no Brasil. As consequências desta crise afetariam várias dimensões do país (econômica, política e social ${ }^{13}$, por exemplo), além de provocar uma redefinição setorial quanto aos rumos propostos para a organização institucional e político-econômica do setor elétrico brasileiro. Tal crise culminou por corroborar para a redefinição do modelo de privatização do setor elétrico do Brasil, ou seja, a mentalidade de que as reformas setoriais deveriam ser orientadas para o mercado começa a ser questionada de forma mais acintosa pelos críticos do modelo de privatização.

\footnotetext{
12 A construção de adequação entre meios e fins.

13 - Um dos impactos percebidos foi o aumento das tarifas, principalmente e em maior intensidade para as classes de consumo de menor renda, o percentual mais pobre do país (GOLDENBERG E PRADO, 2003; ROSA, 2002; SAUER, 2002; IDEC - www.idec.org.br; ILUMINA - www.ilumina.org.br).
} 
Neste quadro de análise sobre a crise do setor elétrico brasileiro de 2001, cabe salientar que a predominância da geração de eletricidade por hidrelétricas, imbrica no mesmo processo a eletricidade e a água e, ambas vinculadas tanto a noções de desenvolvimento e estilos de vida, como também de cidadania.

O fato de o setor elétrico brasileiro ser majoritariamente de geração hidrelétrica, faz com que tecnicamente seja possível controlar, por meio dos reservatórios, os fluxos de maior ou menor quantidade de água para produção de energia elétrica num determinado espaço de tempo. Esta capacidade de controle seria um fator positivo, dado que os investimentos realizados no setor para ampliação no parque gerador ou na transmissão são de médio e longo prazo de maturação.

A orientação política de reduzir os investimentos no setor elétrico (principalmente na geração, dado a exigência de grandes volumes monetários necessários e do longo tempo de maturação), como forma de contenção de gastos. Uma vez em que os investimentos eram encarados como gastos públicos acabaram por contribuir para o desequilíbrio entre a oferta e a demanda por energia elétrica (mesmo com o país apresentando baixo nível de crescimento do PIB no período).

Desde processo se evidencia dois fatores relevantes para a crise, ou uma dupla divergência. A primeira se refere à diminuição dos investimentos na geração e na transmissão do setor elétrico como componente de política de austeridade fiscal do governo. A Eletrobrás estava numa curva descendente de investimentos e os investimentos das próprias empresas (públicas) do setor eram contabilizados como gastos e consequentemente comprometiam as metas do governo para superávit primário para pagamento da dívida pública (ROSA, 2002; SAUER, 2002; GOLDENBERG E PRADO, 2003).

A segunda divergência é que o consumo (pelas diferentes classes de consumidores) crescia numa velocidade maior que a ampliação da capacidade instalada de energia. Analisando o período histórico de 1981 à 2001, fica evidente tal discrepância. Por outro lado, os investimentos em transmissão também estavam abaixo do necessário, inviabilizando com isso um melhor aproveitamento energético nacional. O blecaute de 1999 (no interior do Estado de São Paulo) já 
O SETOR ELÉTRICO BRASILEIRO ENTRE AS TRANSFORMAÇÕES CONTEMPORÂNEAS: o caso da crise elétrica em 2001

evidenciava sinais de deficiência e desgaste na rede de transmissão. Isto porque as disparidades regionais e pluviométricas se integradas poderiam ser vistas de forma sinérgica para o setor elétrico brasileiro.

QUADRO 1 - Capacidade Instalada versus consumo (em \%)

\begin{tabular}{|c|c|c|}
\hline Período & \% Capacidade Instalada & \% Consumo \\
\hline $\mathbf{1 9 8 1 - 1 9 9 0}$ & 4,8 & 5,9 \\
\hline $\mathbf{1 9 9 1 - 2 0 0 1}$ & 3,3 & 4,1 \\
\hline
\end{tabular}

Fonte: SIESE, Eletrobrás. Extraído de SAUER, 2002:194

Os investimentos no setor saíram de US\$13,9 bilhões em 1980, passaram para US\$11,1 bilhões em 1989, para US\$ 7,1 bilhões em 1993, para US\$ 4,5 bilhões em 1995 e US\$ 6 bilhões em 1998 (ROSA, 2002). Demonstrando com isto que os investimentos no setor desde o começo dos anos 1980 foram abaixo do crescimento da demanda por consumo.

Corroborando com está situação ainda havia uma percepção entre diferentes empresas do setor elétrico, do MME e até da ANEEL e da ONS de que a crise no setor poderia ocorrer ainda em 1997. Além de inúmeros outros relatórios técnicos e acadêmicos acerca desta questão (GODENBERG E PRADO, 2003). Apesar de algumas iniciativas, ainda que tímidas ou marcadas pela ineficiência da gestão governamental (Programa de Geração Emergencial, em 1999, e do Programa Prioritário das Térmicas e do Leilão de Capacidade, em 2000), o governo não conseguiu evitar a crise de 2001.

O setor vinha de uma trajetória marcada por uma diminuição dos investimentos no setor e, simultaneamente, pelo constante o aumento do consumo. $O$ governo tinha como orientação política a diminuição dos investimentos porque os via como gastos, ou seja, uma política de ajuste fiscal severa com as empresas do setor. Com isto, tanto os investimentos em novas usinas geradoras, quanto em novas linhas de transmissão ficaram comprometidas (assim como também se atrasou as linhas já em construção e/ou ampliação). 
O caso da terceira linha (rede) de transmissão, ligando Itaipu ao sudeste que até meados de 2003 ainda não estava finalizada é um exemplo. Os investimentos em geração ou mesmo na finalização desta linha entre Itaipu e a região sudeste poderia ter mitigado os efeitos da crise (de 2001), senão, contribuído para evitar a mesma. Isto porque quando a crise foi deflagrada o reservatório de Itaipu vertia água (LEME, 2004). Por outro lado, a interconexão entre as regiões Sudeste-Nordeste também apresentava deficiências, evitando com isto que as diferenças regionais hidrológicas funcionassem de forma estratégica para melhor aproveitamento nacional (várias usinas do nordeste durante a crise também vertiam ${ }^{14}$ águas).

Apesar das disparidades expostas, o governo manteve sua agenda e, em 2001, poucos dias antes da deflagração da crise no setor elétrico (e posteriormente pelo racionamento), o governo anunciava seus propósitos políticos (agenda em políticas públicas) de abrangência mais popular e veiculados pelos meios midiáticos (jornais e revistas de grande circulação), a saber: a) o programa Luz no Campo, para eletrificação rural; b) o programa Reluz, para iluminação urbana ${ }^{15}$. (LESSA, 2001).

Todavia, naquele momento já era sabido sobre a possibilidade de uma crise no setor elétrico devido à redução significativa do volume de água nos reservatórios a níveis de risco extremo. Ocorreu no mínimo uma contradição neste processo de veicular os programas como avanços em áreas até então não atendidas, sem a menor preocupação com a situação real do suprimento de energia. Passava-se a ideia para a opinião pública que o setor elétrico brasileiro estava fora de qualquer risco iminente de crise. Mais do que isso, que estaria em expansão às regiões e atores historicamente excluídos do acesso a eletricidade.

Por outro lado, não se pode afirmar que o governo ficou refém da Fortuna na deflagração da crise no setor elétrico em função dos baixos níveis hidrológicos registrados no período.

\footnotetext{
14 - As águas vertidas por usinas em função de uma baixa capacidade de interconexão entre regiões via redes de transmissão caracterizam como jogar energia potencial fora, ou seja, não se aproveita de uma vantagem técnica e estratégica do setor por decorrência de deficiências e déficits em investimentos na transmissão.

15 - Embora ambos os programas não viessem a funcionar como deveriam durante o tempo do mandato presidencial de FHC.
} 
Primeiramente, porque o setor majoritariamente de fonte hidrelétrica possui condições técnicas para lidar com estas circunstâncias. Em segundo lugar, o setor já vinha desde a década de 1980, passando por sucessivas depreciações e níveis de investimentos sempre abaixo dos necessários a continuidade do desenvolvimento econômico e social do país à níveis sustentáveis e ao próprio equilíbrio setorial.

Neste sentido, o governo não foi pego pela Fortuna, não ficou refém do acaso, mas sim lhe faltou Virtù para conduzir a reforma político-econômica e mais precisamente, para reestruturar o setor elétrico de forma a estrangular suas deficiências e não gerar novas. O governo não foi pego de surpresa pela pouca quantidade de chuvas, mas sim, ficou na expectativa de que se houve um volume de chuvas bom o suficiente para regularizar os índices hidrológicos ele não teria problemas de curto prazo no setor.

Uma vez tendo faltado ao governo Virtù para condução das reformas engendradas no setor elétrico, somadas ao impacto que desde o começo da crise já indicavam que não seriam pequenos tanto na dimensão econômica, quanto na político-eleitoral (eleições de outubro de 2002) e social. Isto porque a eletricidade além de ser um insumo para a produção econômica, também pode ser vista como um indicador social, uma vez que o estilo de vida das sociedades capitalistas - urbano e industrial - se estrutura e é estruturada pela eletricidade mediando tanto as condições de trabalho, como também as condições e qualidade de vida.

Mediante tais circunstâncias, o governo, diretamente por discursos e/ou falas do presidente Fernando Henrique Cardoso aos meios de comunicação (impressos ou televisivos), ou por parte de outros atores do governo (Pedro Parente - Chefe da Casa Civil e presidente da Câmara de Gestão da Crise), começou a transferir culpas na tentativa de retirar qualquer possibilidade de erro por parte do governo.

A primeira tentativa consistiu em alegar que desconheciam a situação crítica em que o setor se encontrava, com baixos níveis dos reservatórios e iminente crise a acontecer se nada fos se feito. $\mathrm{O}$ primeiro escalão do governo não teria sido alertado pelos seus subordinados sobre a gravidade em que se encontrava o setor elétrico brasileiro. Ainda que tal circunstância fosse factível, não deixa de 
indicar problemas de gestão e de estratégias tanto nos níveis burocráticos do Estado, como também de planejamento de médio e longo prazo no país por parte dos governos.

Em seguida, tentou-se justificar a crise a partir da escassez de chuva, ou seja, a culpa seria de "São Pedro", no intuito de atribuir a crise a um fator exógeno, fora de qualquer tentativa de controle por parte do governo. No limite, há uma deficiência estrutural do setor presente em sua construção e consolidação (a hidroeletricidade).

A escassez de chuvas é um fenômeno conhecido e estudado e a montagem do sistema hidrelétrico brasileiro passou pela concepção de poder lidar com este tipo de adversidade/irregularidades. Respeitadas às margens de segurança para funcionalidade do sistema hidrelétrico, previamente estabelecido pelo planejamento (experiência histórica e projeções de oferta/demanda de energia associadas à administração do uso da água dos reservatórios). E garantindo a construção de novas usinas para maior sustentabilidade do sistema em curto, médio e longo prazo, o setor não teria tido problemas de ofertas de energia, ou seja, o fato de ser hidrelétrico traz mais vantagens para o planejamento do que desvantagens (ROSA, 2001).

O setor elétrico brasileiro possui mais vantagens do que desvantagens ${ }^{16}$ em ser hidrelétrico. Todavia, como todo setor requer investimentos constantes (em geração e transmissão) e gestão estratégica para utilizar as diferenças regionais (hidrológicas, tempo e intensidade de chuvas, águas interiores) a favor e não as ter como obstáculos ou estrangulamentos ao desenvolvimento econômico e social do país.

Depois, em função de atritos e conflitos dentro do governo, foi atribuída a culpa aos Ministros de Minas e Energia - MME, justificando que seriam atores com características mais políticas e menos técnicas. Tais atritos no epicentro governamental foram impulsionados pelos choques entre o presidente Fernando Henrique Cardoso - FHC - e o então senador do Partido da Frente Liberal - PFL ${ }^{17}$ - Antônio Carlos Magalhães - ACM -, sendo que este último há tempos era

\footnotetext{
16 - As vantagens e desvantagens nesse argumento se restringem a capacidade de controle e planejamento do setor. Não estão em questão os impactos decorrentes dos empreendimentos hidrelétricos sobre o território, o ambiente e as pessoas (comunidades rurais e indígenas).

17 - Hoje denominado de DEM.
} 
o responsável pela indicação dos ministros do $\mathrm{MME}^{18}$. Aqui, evidencia-se, que parte do problema gerador da crise pode ter sido corroborada pelas consequências geradas pelo tipo de composição política necessária a construção de governabilidade do sistema presidencialista brasileiro.

Por fim, insinuou-se que os culpados pela crise seria a própria população brasileira que historicamente teria mantido uma relação de desperdício de energia elétrica, ou seja, os maus hábitos de consumo de energia e a ausência de racionalidade na forma de lidar com a eletricidade teriam gerado, como consequência negativa, a crise deflagrada em maio de 2001.

A culpa da população como fator causal da crise se manifestou, principalmente, em dois momentos cruciais. Primeiro, seriam culpados pelo consumo excessivo de energia e, em segundo, foram chamados ao dever de poupar energia para evitar uma crise maior, transferindo para a população uma eventual culpa sobre futuros ‘apagões’ e crise no setor. Ou a população agiria com racionalidade no consumo ou seria causa para os seus próprios impactos negativos (causa de seus próprios infortúnios).

A questão da eletricidade e do planejamento de curto, médio e longo prazo nessa perspectiva se desloca do Estado, ao menos em partes substanciais, para a sociedade civil que passaria, por vias de práticas sociais não racionais e não reflexivas a gerar os estrangulamentos econômicos e sociais que as atingia. Não que a racionalidade no consumo por parte do consumidor esteja errada, assim como a necessidade de avanços tecnológicos para obtenção de ganhos de eficiência. Todavia, mediante o quadro em que o setor se encontrava, o governo ao priorizar a estratégia do ajuste fiscal em detrimento dos investimentos (estes também vistos como gastos para fins contábeis do governo/Estado) corroborou com a crise no setor.

Todavia, os alertas as possibilidades de uma crise no setor elétrico não faltaram. Sejam de especialistas e críticos do rumo da reforma, ou mesmo de relatórios de órgãos técnicos do governo

\footnotetext{
18 - Tal situação pode ser caracterizada pela lógica na qual o presidente FHC conduziu o seu governo nas indicações de primeiro escalão ministerial. Ficando a cargo do PFL o Ministério das Minas e Energia, área que sempre tiveram influência. Com a crise e os atritos entre FHC e ACM há um enfraquecimento do PFL no MME, ou seja, o partido começa a perder capacidade de mando e poder na área. Com a eleição do governo Lula e a escolha da Ministra Dilma Rousseff para ocupar o cargo de ministra o PFL perde totalmente a influência sobre esta pasta ministerial.
} 
que já acenavam sobre o risco de uma grave crise no setor devido à combinação de aumento da demanda, insuficiência de investimentos em geração e transmissão e a variabilidade de chuva ${ }^{19}$ (sendo este último não determinante) (SAUER, 2002).

O caso do setor elétrico brasileiro e da crise pela qual passou a partir de maio de 2001, revelou que é um risco muito alto aos governantes, mas, principalmente aos cidadãos e a economia como um todo, quando o Governo utiliza como método de ação política, a aposta ${ }^{20}$ em fatos e fenômenos que ele não controla. Como percebido, a reestruturação do setor elétrico brasileiro foi realizada em parte neste tipo de aposta e, um dos resultados destas escolhas foi à crise de racionamento enfrentada pelo país em 2001/2002.

Reformulando o argumento, poderíamos dizer que as apostas são escolhas e opções de estratégias focadas para determinadas políticas (em detrimento de outras) feitas numa complexa estrutura burocrática e político-institucional que é o Estado, marcado por pressões de diferentes atores sociais (classes sociais, movimentos sociais) e com diversos interesses, além de pressões externas. Ou seja, quem está no governo, precisa constantemente negociar e renegociar as estratégias e conduções a serem seguidas primeiramente dentro do próprio governo, depois em sintonia com a burocracia estatal e os diversos interesses presentes na sociedade.

Considerando que a sociedade moderna, urbana e industrial depende, para seu funcionamento e dinamismo, de um suprimento regular de energia, a estratégia e planejamento setorial nesta questão são centrais para a continuidade do desenvolvimento econômico e social dos países. A falta de planejamento e de escolhas adequadas ao desenvolvimento do setor elétrico brasileiro tende a trazer resultados negativos em diversas dimensões que vão desde a econômica, passando pela

19 - Neste sentido, a crise demonstrou um dos ensinamentos que já estavam presentes em Maquiavel na obra "O Príncipe", de 1513, qual seja: a de que o Príncipe, o governante não deve ficar refém da sorte, mas sim agir com prudência, e Virtù para poder enfrentar com sucesso à parte que ele não governa, ou seja, as condições históricas e os fatos fortuitos da natureza. O Príncipe deve agir racionalmente de forma estratégica em teoria e prática ${ }^{19}$. O governante deve ter Virtù para controlar a Fortuna.

20 - No caso da energia elétrica brasileira, dada a sua estrutura num sistema hidrelétrico com grandes reservatórios, foi feita uma aposta em que choveria mais que a média histórica, com isto não era preciso alarmar a população dos riscos e também poderia se dar continuidade cada vez mais no consumo das reservas de águas dos reservatórios. (LEME, 2011). Como se verificou historicamente tais apostas não foram bem-sucedidas. 
política e atingindo drasticamente a social. Do ponto de vista social, há um aprofundamento das disparidades sociais (que já são gritantes no Brasil, principalmente quando evidenciadas pela grande concentração de rendas como indicado pelo Índice de Gini ${ }^{21}$ ). Isto porque os impactos negativos da crise tendem a atingir de forma desigual os diversos atores sociais, sendo que os historicamente mais desfavorecidos sofrem consequências negativas maiores.

Por outro lado, o país ainda está em débito com uma parcela da população que ainda nem se quer tem acesso à energia elétrica (principalmente algumas populações ribeirinhas e alguns moradores de áreas rurais no Norte e Nordeste do país). Inclusive um dos programas lançados pelo governo pouco antes da crise e, inviabilizado por ela, visava atender a demanda dessas camadas sociais por eletricidade. Já na dimensão econômica, há o agravamento da vulnerabilidade externa e a baixa capacidade de crescimento da economia por apresentar um estrangulamento energético.

Não há como não olhar para a crise do setor elétrico brasileiro ocorrida em 2001 e começo de 2002 sem vinculá-la a opções realizadas no tipo de estratégia econômica que seria adotada e implantada no Brasil. O modelo econômico fundamentado na abertura econômica e comercial/financeira, na desregulamentação, na redução do Estado e nas privatizações (com a entrada de FHC na presidência os serviços públicos entraram na agenda privatista - Energia Elétrica e Telecomunicações), corroborou para a deflagração da crise. Principalmente porque se refletiram na diminuição de investimentos e na baixa capacidade gerencial para dar repostas as necessidades urgentes do setor. Neste caso em particular, ficou evidente que a crença na maior eficiência do mercado, mais evidenciou suas falhas que seus possíveis méritos na concorrência, por exemplo.

\section{ENERGIA ELÉTRICA, CRISE E CIDADANIA}

\footnotetext{
21 - É o Índice utilizado para medir a concentração de renda. O ÍNDICE DE GINI varia de 0 (igualdade máxima) a 1 (desigualdade máxima)
} 
Em relação às consequências da crise para a cidadania, destaca-se que a diversidade com que a sociedade é composta, imagina-se que essa heterogeneidade (se bem aproveitada) pudesse engendrar um código ético em propósito da construção e continuidade do desenvolvimento nacional de forma a mitigar as desigualdades sociais ${ }^{22}$, respeitar e garantir a cidadania de todos indiscriminadamente. Pensar em ampliação da cidadania e/ou exercício pleno da mesma, implica não somente em consolidar a Democracia, como também remete a avanços na gestão e controle do que é público (estatal ou não-estatal ${ }^{23}$ ). Assim como também criar novos desenhos institucionais e novos caminhos de diálogos com as diversas forças sociais presentes na sociedade civil.

Marshall (1967) é um dos autores que evidencia a constituição da cidadania na Inglaterra dentro de processos históricos ocorridos em espaços temporais diferenciados. Para tal análise, o autor divide a cidadania em direitos de primeira geração (civil e político) e de segunda geração $(\text { sociais })^{24}$.

No caso brasileiro, a cidadania é bem mais recente e - se for dividida em direitos de primeira e segundo geração, como o fez Marshall na Inglaterra - não apresentará a mesma linearidade histórica das conquistas dos direitos. No Brasil, os direitos civis, políticos e sociais se constituíram de forma muito mais difusa ${ }^{25}$. Além do mais, essa divisão da cidadania entre direitos civis, políticos e sociais é muito mais uma divisão metodológica para o entendimento de como a cidadania

22 Sabemos que o processo de mitigação das desigualdades sociais existentes no Brasil - que não são pequenas -, extrapola a própria questão da cidadania e da maior participação da sociedade civil na gestão/planejamento do setor público por ter que ser combatida em múltiplas frentes (alfabetização, melhor redistribuição de renda, baixa mortalidade infantil dentre outros aspectos fundamentais), porém são de extrema importância para este processo.

23 Um dos autores que explora esta concepção de público estatal e público não-estatal é o economista Bresser Pereira, 1998.

${ }^{24}$ No caso Inglês, a divisão da cidadania apresentou-se no seguinte arranjo: os direitos civis foram conquistados no século XVIII e abrangiam os direitos individuais de liberdade, igualdade, propriedade, ir e vir, direito à vida (concepção liberal clássica). Os direitos políticos foram conquistados no século XIX e diziam respeito à liberdade de associação, de organização política e sindical, sufrágio universal dentre outras e os direitos sociais, econômicos e creditícios foram conquistados no século XX e abrangeram os direitos ao trabalho, saúde, educação, aposentadoria e etc. É justamente o direito social que tornam real (material) o direito formal (institucional) (MARSHALL, 1967).

25 Para ilustrar, basta evidenciar que alguns direitos trabalhistas (enquanto direitos sociais) foram conquistados na década de 30 e a consolidação plena dos direitos políticos com o sufrágio universal (incluindo votos para os analfabetos) data-se da constituição de 1988. 
constitui-se na história do que uma divisão em si. Não há como pensar a existência de um cidadão que não tenha incorporado culturalmente e garantido institucionalmente os direitos civis, políticos e sociais (mais recentemente também os ambientais e bioéticos), (VIEIRA, 1997).

Ao se constituir dentro de processos históricos, a cidadania não só garantiu direitos aos indivíduos como também os deixou em situação de equidade. Porém, quando a sociedade se depara com uma situação, seja de reforma ou de crise de algum setor essencial à vida dos indivíduos, é preciso tomar cuidado para que a cidadania não seja afrontada. Pois, se essa for afetada, haverá uma tendência de impactar de formas diferenciadas os indivíduos, isso porque o poder de negociação nos órgãos decisórios dos indivíduos é desigual. A parcela de menor poder aquisitivo da sociedade tende a ser mais afetada.

Perante este panorama, a crise elétrica deve ser encarada não só como uma crise do setor elétrico, com repercussão diretamente na economia nacional. Mas também, como uma possibilidade de crise da cidadania, materializada de imediato em impactos diferenciados nos vários estratos de consumidores, onde os de baixa renda tendem a ser mais prejudicados, seja no acesso, seja nas tarifas praticadas. Portanto, pode-se encarar a energia elétrica como indicador de inclusão ou exclusão social, refletindo diretamente na qualidade de ser ou não cidadão.

A crise do setor elétrico brasileiro de um lado e, a cidadania do outro, ambas fazendo parte do mesmo momento histórico, deixa as coisas um pouco mais complicadas e complexas, tratando-se da necessidade de resolução da crise instaurada no setor elétrico em 2001/2002. Isto porque há uma tendência em se realizar escolhas que de forma direta ou indiretamente venham a favorecer uma em detrimento da outra, ou seja, a solução para a crise e a preservação da cidadania foram processos encarados separadamente pelo governo. Muitas dessas escolhas foram debatidas na Câmara de Gestão da Crise de Energia Elétrica (CGCE), resultando em inúmeras resoluções, decretos e quatro Medidas Provisórias (MP) que visavam à superação da crise no setor. A composição da CGCE ficou assim definida:

1. Ministros de Estado

a) Chefe da Casa Civil da Presidência da República, que a presidiu; 
b) Ministro de Minas e Energia, que será o seu vice-presidente;

c) Ministro do Desenvolvimento, Indústria e Comércio Exterior;

d) Ministro da Fazenda;

e) Ministro do Planejamento; Orçamento e Gestão;

f) Ministro do Meio Ambiente;

g) Chefe da Secretaria de Comunicação de Governo da Presidência da República;

h) Chefe do Gabinete de Segurança Institucional da Presidência da República;

2. Dirigentes máximos das seguintes entidades:

a) Agência Nacional de Energia Elétrica - ANEEL;

b) Agência Nacional de Águas - ANA;

c) Banco Nacional do Desenvolvimento Econômico e Social - BNDES; e

d) Agência Nacional do Petróleo - ANP;

3. Diretor-Presidente do Operador Nacional do Sistema Elétrico - ONS;

4. Diretor-Geral Brasileiro da Itaipu Binacional; e

5. Outros membros designados pelo Presidente da República (MP nº 2.198-3, de 28 de junho de 2001, medida em vigor).

A CGCE, ao deliberar e/ou criar uma determinada normatização que visava combater a crise, como o art. $5^{\circ}$ e $13^{\circ}$ da MP n ${ }^{\circ} 2.198-3$, estabeleceu os objetivos do Programa de Redução do Consumo de Energia Elétrica, a saber: a compatibilização da demanda de energia com a oferta por meio da otimização do consumo de energia a setores estratégicos; o regime especial de tarifação ao consumidor segundo os níveis de consumo; entre outros.

O maior problema deste tipo de combate à uma crise, tal como a instada no setor elétrico brasileiro em 2001, é que a superação dela acaba ficando em primeiro lugar, ou seja, acima até mesmo de alguns direitos dos consumidores e cidadãos. Todos acabam pagando de forma e intensidade diferenciadas conforme seu posicionamento na estratificação social (ou de classe). Porém, de forma inversa à prioridade social, os consumidores de baixa renda têm sofrido os

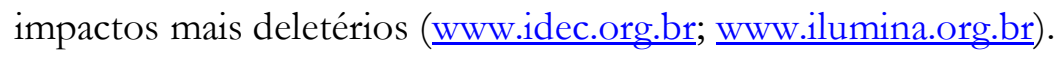


Esses consumidores ainda ficariam mais prejudicados por já se encontrarem em um limite mínimo de gasto de energia elétrica, por um lado e, por outro, por não disporem de condições financeiras para usufruírem dos benefícios da tecnologia para economizarem (as lâmpadas mais econômicas com pouca perda de calor ainda são muito caras) (IDEC, 2001b).

Porém, não é somente os estratos que já vivem em condições precarizadas de consumo elétrico que foram mais prejudicados. Os indivíduos/famílias que por algum motivo já evitavam o desperdício de eletricidade, economizando e racionando os gastos elétricos também foram mais penalizados que aqueles que faziam mau uso do consumo elétrico, dado a forma com que foi calculado as médias com que cada domićlio, comércio ou indústria deveria economizar, (ROSA, 2002; SAEUR, 2002).

Percebe-se que a lógica com que as propostas de superação da crise advindas da CGCE caminharam no sentido de dar centralidade a redução do consumo de energia elétrica. Ainda que de forma direta ou indireta impactasse negativamente setores da sociedade, principalmente o residencial que após o início de reestruturação do setor elétrico - privatização - pagou significativamente mais pela energia elétrica (www.idec.org.br).

Os consumidores residenciais, após as privatizações, tiveram aumentos que dependiam da quantidade consumida mensalmente, sendo que, na média, chegou-se a aumentos da ordem de 108\%. Este percentual é muito superior ao aumento para as classes de consumo industrial, comercial e outras, cujos reajustes variaram de $3,15 \%$ até $26,57 \%$, dependendo da empresa. A nova política tarifária, cuja orientação culminou num resultado assustador, segundo o qual o consumidor de até 30 Kwh, ou seja, o consumidor de baixa renda, sofreu um aumento real (além da inflação) da ordem de $321,45 \%$ (IDEC, 2001B).

Quadro 2 - Aumento real da tarifa de energia elétrica para o consumidor residencial no período de junho de 1994 a agosto de 1999

\begin{tabular}{|l|c|c|c|c|c|c|}
\hline Consumo Mensal & $\begin{array}{c}\text { Junho } \\
\mathbf{1 9 9 4}\end{array}$ & $\begin{array}{c}\text { Agosto } \\
\mathbf{1 9 9 9}\end{array}$ & $\begin{array}{c}\text { Diferença } \\
\mathbf{( R \$ )}\end{array}$ & $\begin{array}{c}\text { Variação } \\
\mathbf{( \% )}\end{array}$ & Inflação & $\begin{array}{c}\text { Aumento } \\
\text { Real (\%) }\end{array}$ \\
\hline Até 30 Kwh & 0,68 & 4,83 & 4,15 & 613,34 & 69,26 & 321,45 \\
\hline
\end{tabular}


O SETOR ELÉTRICO BRASILEIRO ENTRE AS TRANSFORMAÇÕES CONTEMPORÂNEAS: o caso da crise elétrica em 2001

Alessandro Andre Leme

\begin{tabular}{|c|c|c|c|c|c|c|}
\hline Até $50 \mathrm{Kwh}$ & 1,75 & 8,05 & 6,30 & 360,00 & 69,26 & 171,78 \\
\hline Até 100 Kwh & 4,44 & 16,10 & 11,70 & 262,61 & 69,26 & 114,24 \\
\hline Até $200 \mathrm{Kwh}$ & 13,78 & 32,20 & 18,40 & 133,67 & 69,26 & 38,06 \\
\hline Até $220 \mathrm{Kwh}$ & 16,25 & 35,42 & 19,20 & 118,00 & 69,26 & 28,80 \\
\hline Até $300 \mathrm{Kwh}$ & 26,1 & 48,29 & 22,20 & 85,02 & 69,26 & 9,31 \\
\hline Até $400 \mathrm{Kwh}$ & 38,41 & 64,39 & 26,00 & 67,62 & 69,26 & $-0,97$ \\
\hline Até 500 Kwh & 50,73 & 80,49 & 29,80 & 58,66 & 69,26 & $-6,26$ \\
\hline Até $700 \mathrm{Kwh}$ & 75,36 & 112,69 & 37,30 & 49,54 & 69,26 & $-11,65$ \\
\hline Até 900 Kwh & 99,99 & 144,38 & 44,40 & 44,40 & 69,26 & $-14,69$ \\
\hline Até 1100 Kwh & 124,60 & 177,08 & 52,5 & 42,10 & 69,26 & $-16,05$ \\
\hline
\end{tabular}

Fonte: IDEC (www.idec.org.br)

* O Instituto Brasileiro de Defesa do Consumidor (IDEC) elaborou o quadro com informações extraídas da ANEEL.

Outro aspecto ligado à crise do setor elétrico foi o processo de privatização engendrado no país na década de 1990. Para o entendimento do porquê esse processo corroborou para a crise é preciso analisar as duas motivações que a causaram, a saber: motivações estruturais e motivações conjunturais.

Um dos aspectos estruturais foi à importância do capital estrangeiro para consolidação do parque gerador hidroelétrico brasileiro no final da década de 1960 e, praticamente em toda a década de 1970.

A inviabilidade de o Brasil realizar empréstimos especiais junto ao FMI para investimentos em infraestrutura, no final da década de 1980, prejudicou bastante a capacidade do Estado (governo Federal e estadual) em investir na ampliação da geração e das redes de transmissão. Outro fator que pode ser considerado estrutural foi o aumento significativo do consumo de água dos múltiplos usuários na história recente brasileira, como por exemplo, o maior consumo de água pelo setor 
O SETOR ELÉTRICO BRASILEIRO ENTRE AS TRANSFORMAÇÕES CONTEMPORÂNEAS: o caso da crise elétrica em 2001

urbano $^{26}$ e da agricultura (irrigação) que atingem de forma direta a capacidade de água nos reservatórios (usinas hidroelétricas), (LEME,2000).

Os aspectos conjunturais referem-se às consequências do processo de privatização em si. A forma com que a privatização ocorreu no Brasil, especialmente a do setor elétrico, fez com que houvesse uma redução drástica nos investimentos para geração de energia elétrica. Isso porque a opção do governo ao privatizar as empresas de distribuição ou de geração, foi em evitar ao máximo os gastos e/ou investimentos realizados pelas empresas para deixá-las mais atrativas para a competição no mercado e para o interesse do capital privado (nacional ou preferencialmente internacional).

O governo, quando optou pela não realização de investimentos ou por investimentos de pouco valor monetário enquanto estivesse privatizando as empresas estatais de distribuição e geração de energia elétrica, fez com que houvesse (ampliasse) um crescente desequilíbrio entre a oferta e a demanda elétrica. Outros fatores consequentes desta orientação política foram os baixos investimentos realizados para a ampliação das redes de Transmissão de Alta Tensão, cujas benesses seriam uma maior integração nacional e regional da oferta elétrica brasileira, o que ocasionaria um melhor aproveitamento (otimização) da capacidade elétrica do país.

Tanto o primeiro, quanto segundo fator incidiu diretamente como causas da crise. Com a crise deflagrada - com parte significativa do setor elétrico de distribuição e geração privatizado - o governo anunciou investimentos de aproximadamente R\$ 10 bilhões do BNDES em 3 anos na geração, transmissão e distribuição ${ }^{27}$.

A ausência de investimentos no setor elétrico durante o processo de privatização e o não cumprimento da realização dos investimentos que ficaram a encargo das novas concessionárias (privadas) do setor elétrico, também colaboraram para a deflagração da crise.

A variação pluviométrica sempre esteve presente no cenário brasileiro, ou seja, ano a ano no Brasil, a geração de energia hidroelétrica depende da variação das chuvas. Sendo que, desde a

\footnotetext{
26 Como ilustração desse exemplo, temos o sistema Cantareira que exporta cerca de $30 \mathrm{~m}^{3} / \mathrm{s}$ de água da bacia Piracicaba para a grande São Paulo.

27 Jornal Folha de São Paulo, Caderno Dinheiro - B7, de 8 de agosto de 2001.
} 
década de 1960 que não havia mais ocorrido falta de energia elétrica, mesmo nos momentos históricos de vazão muito baixa, como a ocorrida em 1971 (aproximadamente 60\% da média).

Em 1990, embora a média da vazão também tenha sido baixa (porém, ainda um pouco acima da média de 1971) não dá para atribuir a ela o fator fundamental para a crise (como já argumentado acima). Vários foram os períodos de seca intercalados historicamente e nem por isso houve crises de energia em todos eles. Não é possível justificar uma crise assentada na média de vazão quando se vem ano a ano investindo aquém do que o setor precisaria para funcionar (ROSA, 2002). Portanto, advoga-se que a junção dos fatores estruturais e conjunturais presentes no setor elétrico seriam os principais causadores da crise elétrica.

A privatização ainda teve outro desdobramento que em época de crise se acirrou mais, qual seja: uma mudança substancial na relação que uma empresa prestadora de serviços públicos mantém com a sociedade civil. Ao passo que numa empresa estatal (por mais que seu funcionamento não seja satisfatório) há uma relação em que o usuário é visto como cidadão, logo, portador de toda uma dimensão social de direitos e deveres que, por sua vez, excede a relação usuário/empresa. Com a privatização e gestão destas empresas pelo capital privado, ocorre uma mudança essencial na relação entre os usuários e as empresas. Os usuários passam a ser vistos como consumidores, e o consumo é apenas uma dimensão da cidadania, mas não sua totalidade.

Os fatores estruturais, por um lado e, os conjunturais, por outro, lançaram um desafio sobre como melhorar a eficiência e eficácia dos serviços de utilidade pública sem oneração estatal e prejuízo aos usuários. E ao mesmo tempo, preservar a cidadania, a qualidade dos serviços e um preço acessível da energia elétrica a ser paga pelos usuários (dado que parte da nossa geração é feita por energia já amortizada, chamada de velha, cujo custo de operação é menor).

Muitas são as possibilidades críticas de avaliação e análise da crise que o setor elétrico passou no ano de 2001. Muitos também são os atores que de forma discursiva, por meio de estudos ou por implantação de políticas, também apresentaram criticidade sobre a crise e o chamado racionamento. 
Além do mais, alguns atores responsáveis por órgãos governamentais, embora favoráveis à reestruturação como a ocorrida no setor elétrico brasileiro, não deixaram de enumerar suas críticas.

Para a $\operatorname{CSPE}^{28}$ (Comissão de Serviços Públicos de Energia de São Paulo), a crise no setor e o racionamento, fizeram com que se ampliassem muito os trabalhos, como complicador, a comissão ainda teve que enfrentar os problemas decorrentes da fase de implantação em que estavam (estrutura e recursos humanos).

A CSPE vinha se consolidando e foi obrigado a fazer uma ampliação extraordinária no quadro de funcionários durante este período para ser possível atender a demanda relativa ao esclarecimento à população e a fiscalização de demais atividades. Além daqueles normais do serviço de energia vigente. Para tal, a comissão contou com o apoio da USP por meio de consultoria técnica e econômica. Por outro lado, a CSPE também reconhece que alguns transtornos foram gerados, mas no final ainda acham que o saldo foi positivo:

$\mathrm{Na}$ verdade, houve uma grande encrenca geral nesse país, não só com os consumidores residenciais, mas também industriais e uma série de sustos iniciais que a consolidação do racionamento e sua implantação acabaram desmistificando algumas coisas... A economia não tomou aquele baque (impacto) esperado pelas pessoas que anteciparam as características de consumo. Não há situações gritantes de problemas gerados pela solicitação de redução do consumo e no final nós estamos aprendendo que devemos evitar o desperdício, ou seja, ao voltar a normalidade iremos consumir menos energia de uma forma geral para os mesmos usos (COMISSÁRIO CHEFE DO GRUPO COMERCIAL E DE TARIFA DA CSPE, $\left.2001^{29}\right)$.

$\mathrm{Na}$ visão da CSPE, assim como da Secretaria de Energia do Estado de São Paulo, a crise e o racionamento, embora portadores de alguns constrangimentos, acabaram por ser positivo para o Estado e para o país porque engendrou um comportamento mais responsável do consumidor no que se refere à utilização de energia e também para evitar o desperdiço.

\footnotetext{
28 - Posteriormente incorporada na Agência Reguladora de Saneamento e Energia do Estado de São Paulo ARSESP. Juntando sobre sua responsabilidade e fiscalização o gás canalizado, o saneamento e a energia elétrica.

29 - Entrevista realizada pelo pesquisador.
} 
O governo do Estado, por meio do Decreto n ${ }^{\circ}$ 45.765/01, instituiu o Programa Estadual de Redução e Racionalização do Uso de Energia no âmbito dos órgãos da administração pública direta, das autarquias, das fundações instituídas e mantidas pelo Poder Público e das empresas onde o Estado tinha participação majoritária em reduzir o consumo em $20 \%$.

O racionamento teve alguns constrangimentos, mas que rapidamente foram superados, e só não foram menores porque houve uma demora, ou seja, o governo retardou a racionamento até um limite crítico. Essa morosidade do governo em decretar o racionamento começou a chegar em situações criticas o que obrigou em maio e junho esta redução drástica de $20 \%$ em média para todo setor elétrico (ASSESSOR DO SECRETÁRIO DE ENERGIA DO ESTADO DE SÃO PAULO, 2001 ${ }^{30}$.

As falas institucionais da CSPE e da Secretaria de Energia do Estado de São Paulo, embora reconheçam que houve deficiências, nos parecem veicular um discurso centrado na lógica do crescimento e dos avanços pelas catástrofes enfrentadas. Ou seja, uma lógica sempre reativa e não de forma proativa, como recomenda algumas reflexões, ou mesmo como recomendaria qualquer gestão mais estratégica.

Justamente durante esses momentos de crise que se evidenciam algumas das contradições entre o que o governo veicula discursivamente e o que ele realiza como prática política. O discurso governamental é no sentido de fazer política com planejamento e na prática (no setor elétrico em particular) apresenta pouco planejamento e muita reação às mazelas decorrentes das decisões políticas tomadas, tal como vivenciamos no setor elétrico em esfera federal (governo FHC) e, principalmente em esfera estadual (como o caso paulista, como o Estado que mais avançou nas privatizações no setor tanto na distribuição, quanto na geração).

As análises realizadas tanto pela CSPE como também pela Secretaria de Energia do Estado de São Paulo tanto no que se refere à reestruturação do setor, quanto ao próprio processo de crise que se instalou no país em 2001, parte quase que restritamente de uma orientação conjuntural marcada por uma análise reducionista de custo/benefício, principalmente quando se trata de

\footnotetext{
30 - Entrevista realizada pelo pesquisador.
} 
analisar a crise e o racionamento no setor elétrico. Desta forma, não se dá, primeiramente, para reduzir toda discussão aos fatores conjunturais, é necessário também compreender o setor pelos fatores estruturais, pois muitas políticas postas em prática no presente só vão apresentar muitos de seus impactos no médio e longo prazo.

Em segundo lugar, não dá para lidar com o racionamento de forma homogênea, nem mesmo o consumidor. Afinal, há vários estratos de consumidores segundo a capacidade de consumo elétrico e portadores das mais variadas rendas. Sendo assim, veicular estritamente que o racionamento foi positivo porque fez com que a parcela que fazia mau uso da energia foi obrigada a evitar o desperdiço é desconsiderar a diversidade existente e plural presente na sociedade e na forma com que se relacionam com a energia elétrica.

Já as críticas do IDEC ao processo de reestruturação do setor elétrico brasileiro, particularmente o Paulista e a crise - racionamento - de energia elétrica também não faltaram:

No racionamento faltou orientação sobre a necessidade de economizar, de evitar o desperdiço, a sociedade civil ficou as margens das discussões da reestruturação do setor elétrico brasileiro, por isso que teve tão poucas informações... $\mathrm{Na}$ perspectiva do IDEC a crise que o setor passou racionamento - decorreu de falta de investimentos no setor, desde 1997 em eventos do setor o Instituto tem escutando os especialistas falarem sob uma possível crise no setor elétrico. O governo pecou por não ter investido mais, por não ter propiciado uma ampla campanha de informação para o consumidor que esta crise viria (porque possivelmente o governo já sabia). O racionamento, a falta de energia e a falta de investimento no setor foram traumáticos para o consumidor (www.idec.org.br).

As críticas decorrentes do IDEC são no sentido de exacerbar a pouca participação da sociedade civil no processo de reestruturação do setor elétrico brasileiro por falta de espaços criados e institucionalizados pelo governo. Outra crítica feita, e talvez a principal, em função do próprio fim último do IDEC se refere aos impactos gerados aos consumidores residenciais, principalmente os de baixa renda, tanto no processo em si de racionamento, como nas tarifas praticadas e no acesso aos serviços. Por fim, outro fator que corroborou com tais impactos foi às 
brechas contratuais que no limite acabavam por beneficiar as concessionárias em detrimento dos consumidores.

\section{Considerações Finais}

Como percebido, o racionamento e a crise no setor elétrico como um todo foi resultado de diversos fatores conjunturais e estruturais contidos no setor e que não foram equacionados de forma a prevenir e/ou evitarem o mal estar passado, impactando por decorrência algumas camadas de consumidores residenciais, além é claro de desestruturar todo um setor estratégico para a economia e o país, ou seja, para o desenvolvimento econômico e social do Brasil.

A compreensão da crise no setor elétrico, ocorrida em 2001, consistiu em um conjunto de argumentos acerca das ações, discursos e estratégias muitas vezes adotadas e definidas pelo conjunto de atores políticos e administrativos/burocráticos que compõem o Estado Moderno, principalmente o brasileiro no período supra referido. Por outro lado, as decisões e escolhas efetuadas no âmbito governamental tiveram ligação direta e/ou indiretamente com crise instalado no setor elétrico brasileiro em 2001.

Foi perante um conjunto de fatores postos e conhecidos que a crise se instaurou, isto porque o governo fez sua opção político-econômico e institucional, onde algumas apostas foram feitas, embora a prudência recomendaria uma outra postura. Em outras palavras, a aposta do governo no ajuste fiscal para conter os gastos públicos para garantir o superávit primário para abatimento da dívida pública. Com isto, a divergência entre capacidade instalada e ampliação de redes de transmissão (Itaipu/Sudeste e Sudeste/Nordeste) foi se deteriorando cada vez mais, uma vez em que os investimentos no setor ficaram abaixo do necessário.

Neste sentido, a crise no setor - além dos fatores externos - foi marcada por sucessivos equívocos de planejamento, coordenação e gerenciamento estratégico, chegando ao ponto em que o governo começou a contar com a Fortuna para não entrar em crise.

Outro fato resultante da implementação das reformas neoliberais no setor neste período foi o impacto maior no aumento das tarifas mais caras justamente para as famílias e indivíduos localizados nas estratificações mais baixas, ou seja, os mais pobres, evidenciando que os impactos 
O SETOR ELÉTRICO BRASILEIRO ENTRE AS TRANSFORMAÇÕES CONTEMPORÂNEAS: o caso da crise elétrica em 2001

Alessandro Andre Leme

das reformas foram desiguais nos seus efeitos negativos sobre a população presente nas estratificações sociais mais baixas.

Por fim, o racionamento, a crise do setor elétrico brasileiro, e do paulista em particular (por ter sido um dos mais efetivos), devem ser encarados como um exemplo historicamente determinado de escolhas políticas feitas e implantadas em um setor de infraestrutura essencial para a dinâmica social da modernidade. E, seus respectivos efeitos e impactos (negativos e/ ou positivos) são os marcos concretos das deficiências e contradições desta opção que se centrou numa orientação político-econômica de reformas e estratégias de desenvolvimento voltadas para o mercado - liberalização, ou como se convencionou a falar/escrever, as orientações neoliberais.

\section{Referências bibliográficas}

ABRUCIO, F. L.; COSTA, V. M. F. Reforma do Estado e o contexto federativo brasileiro. São Paulo: Fundação Konrad-Adenauer-Stiftung, 1998.

BERMANN, C. Energia no Brasil: para quê? para quem? - Crise e alternativas para um país sustentável. São Paulo: Editora Livraria da Física; Fase, 2002

BIONDI, A. O Brasilprivatizado: um balanço do desmonte do Estado. São Paulo: Fundação Perseu Abramo, 1999.

BRESSER-PEREIRA, L. C. A reforma do estado dos anos 90: lógica e mecanismos de controle. Brasília: Ministério da Administração Federal e Reforma do Estado, 1997 (Cadernos MARE da reforma do Estado; v. 1)

CARDOSO, F. H. As ideias e seu lugar. Petrópolis, RJ: Vozes, 1993.

FERNANDES, F. 1981 Sociedade de classes e subdesenvolvimento. Rio de Janeiro: Zahar, 1981.

FERREIRA, C. K. L. Privatização do setor elétrico no Brasil. In: PINHEIRO, A. C.; FUKASAKU, K. (Edits.) A Privatização no Brasil - o caso dos serviços de utilidade pública. Brasília: BNDES, 2000.

FURTADO, A. T. Mudança institucional e inovação na indústria brasileira de petróleo. Rio de Janeiro. IX Congresso Brasileiro de Energia e IV Seminário Latino-Americano de Energia: Anais, 2002. 
O SETOR ELÉTRICO BRASILEIRO ENTRE AS TRANSFORMAÇÕES CONTEMPORÂNEAS: o caso da crise elétrica em 2001

GOLDENBERG, J. E PRADO, L. T. S. Reforma e crise do setor elétrico no período FHC.

Revista tempo Social - USP, 2003.

LEME, A.A. A reestruturação do setor elétrico brasileiro: privatização e crise em perspectiva. In:

Uso e Gestão dos Recursos Hídricos no Brasil (org.) Felicidade, N; Martins, R.C.; Leme, A.A., São Carlos, SP: RiMa, 2001.

LEME, A. A. Desenvolvimento e sociologia: uma aproximação necessária. Revista Sociedade e Estado, Brasília, v. 30, n. 2, p. 495-527, ago. 2015.

LEME, A. A. Estado e privatização: um debate sociológico, uma questão política. Civitas: revista de ciências sociais, Porto Alegre, v. 11, n. 2, p. 339-360, maio/ago. 2011.

LEME, A. A. Globalização e reformas liberalizantes: contradições na reestruturação do setor elétrico brasileiro nos anos 90. Revista Sociologia e Política, Curitiba, n. 25, p. 165-186, nov. 2005. LEME, A. A. Neoliberalismo, globalização e reformas do estado: reflexões acerca da temática. Barbarói, Santa Cruz do Sul, n. 32, p. 114-138, jan./jul. 2010.

LEME, A. A. State and electricity sector in Brazil: privatization and reform in perspective. International Journal of Social Science Tomorrow, v. 1, n. 2, abr. 2012.

LEME, A.A. State energy and development: hydroelectricity in perspective and criticism in Brazil. In: BILIBIO, C.; HENSEL, O.; SELBACH, J. F. (Org.). Sustainable water management in the tropics and subtropics: and case studies in Brazil. Jaguarão: UNIPAMPA, 2011b. v. 2.

LESSA, C. (org.). O Brasil a luz do apagão. Rio de Janeiro: Palavra \& Imagem, 2001. LONGO, R. \& BREMANN, C. Avaliação do processo de reestruturação do setor elétrico brasileiro: das propostas à realidade. In: CONGRESSO BRASILEIRO DE ENERGIA: IV SEMINÁRIO LATINO-AMERICANO DE ENERGIA, 9, Rio de Janeiro. Anais. Rio de Janeiro: Coppe-UFRJ, 2002.

MAQUIAVEL, Nicolau, “O Príncipe”, in Os Pensadores, S.P., Nova Cultural, 1991.

MARSHALL, T.H. Cidadania, classe social e status. Rio de Janeiro: Zahar Editores, 1967.

PETRAS, J. Armadilha neoliberal e alternativas para a América Latina. São Paulo: Xamã, 1999. 
O SETOR ELÉTRICO BRASILEIRO ENTRE AS TRANSFORMAÇÕES CONTEMPORÂNEAS: o caso da crise elétrica em 2001

PIRES, J. C. L. Politicas regulatórias no setor de energia elétrica: a experiência dos Estados Unidos e da União Europeia. Rio de Janeiro: Banco Nacional de Desenvolvimento Econômico e Social, 1999 ROSA, L.P. A crise de energia elétrica: causas e medidas de mitigação. In. Política energética e crise de desenvolvimento. São Paulo: Paz e Terra, 2002.

ROSA, L.P. Energia no Brasil e no Reino Unido: possibilidades de cooperação. Trabalho apresentado no Ministério das Relações Exteriores, setembro de 1997.

ROSA, L. P.; TOLMASQUIM, M. T. E PIRES, J. C.L. A reforma do setor elétrico no Brasil e no mundo: uma visão crítica. Rio de Janeiro: Relume Dumará: Coppe, UFRJ, 1998.

SADEK, M. Tereza, "Nicolau Maquiavel: o cidadão sem fortuna, o intelectual de virtu” in WEFFORT, F. (org.) Os clássicos da política, S.P., Ed. Ática, 2001.

SALLUM JR., B. O Brasil sob Cardoso: neoliberalismo e desenvolvimento. Tempo Social: revista de Sociologia da USP. V11, n.2, 1999.

SAUER, I. Energia elétrica no Brasil contemporâneo: a reestruturação do setor, questões e alternativas. In. Política energética e crise de desenvolvimento. São Paulo: Paz e Terra, 2002.

SAUER, I. Metamorfoses do Estado Brasileiro no final do século XX. Revista Brasileira de Ciências Sociais, vol. 18, nº 52/junho, 2003.

TOLMASQUIM, M. T. \& CAMPOS, A. F. A reforma do setor elétrico em perspectiva. In: CONGRESSO BRASILEIRO DE ENER- GIA, 9, Rio de Janeiro. Anais.... Rio de Janeiro: COPPE/UFRJ, v. 1, p. 454-459, 2002.

VELASCO JR., L. 1997. A economia das políticas públicas: fatores que favoreceram as privatizações no período 1985-1994. Rio de Janeiro: Banco Nacional de Desenvolvimento Econômico e Social, 1997. 